\title{
FACTORS AFFECTING INFORMATION UTILIZATION IN COFFEE PRODUCTION PACKAGES AMONG SMALLHOLDER FARMERS IN WEST ETHIOPIA
}

\author{
Alemu Mulatu Gutama*12, Guta Regasa Megerssa ${ }^{2}$, Akalu Dafisa Sima² \\ ${ }^{1}$ Department: Ministry of Agriculture and Natural Resources, Western Wollega, Ethiopia \\ ${ }^{2}$ Department: Rural Development and Agricultural Extension, Jimma University, Ethiopia
}

Corresponding Author’s E-mail: jiineguta2014@gmail.com

\begin{abstract}
The main objectives of the study were intended to investigate factors affecting coffee production packages information utilization by smallholder coffee growers in Ethiopia.Cross sectional research design and two stage sampling techniques were used to select sample households. The data were collected from both primary and secondary sources. The data was analyzed using descriptive and inferential statistics to describe factors affecting information utilizations in coffee production packages. Ordered logistic regression model was used to analyze the factors affecting information utilization in coffee package. From 16 explanatory variables hypothesized: age, household size, on-farm income, coffee farm size, radio use, social participation, farmer's willingness to share information and farmers perception toward coffee package practice were found to be significant at less than $1 \%$ and $5 \%$ significance level. In a nutshell, there are different demographic, economic, institutional and psychological factors which result in the reduction of coffee yields. Therefore, rural development strategy should give priority attention to promote coffee production package technologies by providing sustainable technical services through training practically by introducing coffee demonstration site and managing the existing old coffee farm in the study area.
\end{abstract}

Keywords: Coffee Producers, Information Utilization, Ordered Logit Model

http://dx.doi.org/10.21776/ub.agrise.2019.020.3.1

Received 22 may 2019

Accepted 27 July 2019

Available online 25 August 2019

\section{INTRODUCTION}

Ethiopia is the center of origin and diversity of Arabica coffee (Anthony et al., 2001) and important source of coffee genetic resources for the world coffee industry. Coffee production is a vital to the Ethiopian economy with about 15 million people directly or indirectly deriving their livelihoods from it (Tefera and Tefera, 2013). Report of Ethiopian Market Overview (2018) coffee exports accounts 30\% among the other agricultural products. However, the National average productivity of the coffee is not more than 6-7 quintal clean coffee from a hectare which is very small amount (Tesfu, 2012). Lack of dissemination of agricultural information from appropriate sources across smallholder coffee growers were a major difficulty to access and utilize agricultural information and utilization of relevant accurate and up-to-date agricultural information would ensure increased agricultural productivity (Banmeke and Ajayi, 2008). Due to this smallholder farmer who produces coffee in Ethiopia still follows traditional farming systems of production and management practices due to the limited utilization of agricultural information (Tefera and Tefera 2013). In the study area the implementation of coffee package practices was utilized in different level. This variation resulted in 
low production; low marketable products due to low quality product. This might be due to limited sources of information and personal, social, economical, institutional and psychological factors existed in the area.

The use of information in agriculture sector is enhances farming productivity in a number of ways (Bachhav, 2012). Lack of information dissemination, utilization and limited coverage of extension across the agricultural supply chain is a major concern in the developing world including Ethiopia (CSA, 2015). In the study area even though there is potential coffee production, the smallholder farmers frequently harvest low production in which the yield obtained from hectare was not more than 5 quintal of clean coffee which is below the national average as the report of (CTMDA, 2017). The reason behind for the reduction of production low utilization modern practice which is theoretically, shown by Meyer's (2000) model that small-scale farmers are not aware of modern practices and are dependent on their local knowledge. In the study area no any research was conducted so far which identify the sources of information in coffee packages and utilization, and locally specific factors affect modern coffee technology packages and its practices. So, this is the remaining parts of the problem to conduct the study for appropriate policy intervention to overcome the problems. Therefore, these gaps call for the study and motivated the researcher to conduct in the area. Therefore, investigating factors affecting information utilization in coffee production packages by smallholder coffee growers in the study area are important so as to endeavor future direction and policy recommendation.

\section{RESEARCH METHODS}

A cross-sectional survey design was used in this study. Both quantitative and qualitative data types were collected for this study from Primary and secondary data. Quantitative data were gathered using pre-tested, structured interview schedules from the respondents. Primary qualitative data, collected from Focus Group Discussion (FGD) and key informant interviews. Secondary data was collected from published and unpublished sources; documents. Two stage sampling techniques were used to select sample households. By using systematic random sampling, sample was taken from the total list of respondents proportionally in each Kebeles. The sample size was determined by using (Yemane, 1967).

$$
\mathrm{n}=\frac{\mathrm{N}}{1+\mathrm{N}(\mathrm{e})^{(2)}}
$$

Where: $\mathrm{n}=$ Number of samples, $\mathrm{e}=$ maximum variability or margin of error $8 \%, \mathrm{~N}=$ total number of households; $1=$ probability of the event occurring.

$$
\mathrm{n}=\frac{4088}{1+4088(0.08)^{(2)}}=151
$$

In this study, quantitative data were analyzed using descriptive statistics and inferential statistic. Qualitative data were analyzed in the form of statements or narration. Besides, it was analyzed on the spot to minimize the risk of overlooking important information used for triangulation to reinforce the information obtained from, quantitative primary data. Ordered logistic regression was used in this study since the response variables have a natural ordering and assess the influence of the explanatory variables on the dependent variable. According to Green (2008), the functional form of ordered logit model was specified as:

$\tilde{\mathrm{y}}=\sum_{k-1}^{k} \beta \mathrm{k} * \mathrm{xk}+\varepsilon \ldots \ldots \ldots \ldots \ldots \ldots \ldots \ldots \ldots \ldots \ldots \ldots \ldots$

$\tilde{y}=$ latent variable and can be thought of as the underlying tendency of an observed phenomena

$\mathrm{e}=$ is disturbance term assumed to follow a certain symmetric distribution with zero mean such as nominal or logistic distribution. What do observe is

$$
\begin{aligned}
& y=1 \text { if } \tilde{y} \leq \mu 1, \\
& y=2 \text { if } \mu 1<\tilde{y} \leq \mu 2, \\
& y=3 \text { if } \mu 2<\tilde{y} \leq \mu 3, \\
& y=j \text { if } \mu j-1<\tilde{y}
\end{aligned}
$$

Where $y$ is observed in $\mathrm{j}$ number of ordered categories, $\mu$ are unknown threshold parameters separating the adjacent categories to estimate with $\beta s$. The general form of the probability that the observed $y$ fall to category $\mathrm{j}$ and the $\mu$ s and the $\beta \mathrm{s}$ was estimated with ordinal logit model is

$$
\operatorname{Prob}(y=j)=1-L\left(n j-\sum_{k=1}^{k} \beta x k x\right) \ldots .2
$$




\section{RESULTS AND DISCUSSION}

\section{Factors Affecting Information Utilization in Coffee Production Packages}

\section{Demographic Factors}

Age is one of the important explanatory variables that affect information utilization. As indicated in (Table 1) below, the mean age for low, medium and high coffee package information utilization was $48.54,45.11$ and 50.88 with the standard deviations of $6.90,6.99$ and 8.20 respectively. The result of mean test, using one-way ANOVA for information utilization in coffee package categories were $(F=6.549$ and $P=0.002)$ and statistically significant difference among the respondents in low, medium and high information utilization in coffee packages and practices.

In (Table 1) below, the total mean average family size of low, medium and high information utilization categories was 3.77 with the standard deviation of 1.40. The mean household size of low, medium and high coffee package information categories was $3.25,3.88$ and 4.88 with the standard deviation of $1.45,1.28$ and 1.09 respectively. One-way ANOVA test result shows that, information utilization $(\mathrm{F}=9.943$ and $\mathrm{P}=$ 0.000 ) significant mean difference between low, medium and high categories at $1 \%$ significant level based on their household size.

Table 1: Relationship of demographic variables with information utilization

\begin{tabular}{lllrrrrrr}
\hline \multicolumn{2}{c}{ Categories } & $\mathrm{N}$ & Mean & S. Dev & Minimum & Maximum & $\mathrm{F}$ & $\mathrm{P}$ \\
\hline \multirow{2}{*}{ Age of } & Low & 52 & 48.54 & 6.90 & 34.00 & 64.00 & & \\
household & Medium & 83 & 45.11 & 6.99 & 33.00 & 66.00 & & \\
head & High & 16 & 50.88 & 8.20 & 40.00 & 69.00 & & \\
& Total & 151 & 46.90 & 7.35 & 33.00 & 69.00 & $6.549 * *$ & 0.002 \\
\hline \multirow{3}{*}{ Household } & Low & 52 & 3.25 & 1.45 & 0.75 & 7.90 & & \\
size & Medium & 83 & 3.88 & 1.28 & 1.00 & 7.15 & & 0.000 \\
& High & 16 & 4.88 & 1.09 & 3.10 & 7.20 & & \\
\hline \multirow{4}{*}{ Education } & Total & 151 & 3.77 & 1.40 & 0.75 & 7.90 & $9.943 * * *$ \\
Level & Low & 52 & 4.37 & 2.85 & 0.00 & 12.00 & & \\
& Medium & 83 & 6.19 & 2.89 & 0.00 & 12.00 & & 0.001 \\
\hline
\end{tabular}

Source: Own study (2017); Note that *** and ** significant at $1 \%$ and 5\% probability level, respectively, N: sample size

In (Table 1) above the total mean average education level of low, medium and high information utilization categories was 5.60 with the standard deviation of 2.96 grades respectively. The mean education level of household in low, medium and high level categories were 4.37, 6.19 and 6.56 with the standard deviation of $2.85,2.89$ and 2.48 grades respectively. The one-way ANOVA test result shows that, information utilization $(\mathrm{F}=7.657$ and $\mathrm{P}=0.001)$ is a significant mean difference among low, medium and high categories at $1 \%$ significant level.

\section{Economic factors}

The total mean annual on-farm income of total sample respondents was 23911 with the standard deviation of 15117 . The mean annual income and standard deviation of low, medium and high information utilization was 14080, 25294, 48686 and 8429, 12504, 13733 Ethiopian Birr respectively. Further analysis using one-way ANOVA result indicates that, there is statistically significant mean difference between low, medium and high utilization $(\mathrm{F}=57.616$ and $\mathrm{P}=0.000)$ categories at less than $1 \%$ significance level based on their on-farm income they earns. From (Table 2) below the total mean annual off-farm income of sample respondents were 2863 with the standard deviation of 1987 . The mean average off farm income of low, medium and high was 2256, 3077 and 3726 ET Birr with the standard deviations of 1251, 2223 and 2197 respectively. The results of the mean test using one-way ANOVA indicated that, there is a significant difference between the respondent categories at $(\mathrm{F}=4.63$ and $\mathrm{P}=0.011)$ significant level depends on their off-farm income.

Coffee farm size is also unique important factor decided information utilization in coffee 
packages and practices. The assessment result shown in (Table 2) above, the mean total of coffee farm size was 1.66 ha with the standard deviation of 0.47 ha, respectively. The mean average of coffee farm size between low, medium and high category was $1.36,1.71$ and 2.38 with the standard deviation of $0.35,0.36$ and 0.41 ha respectively. The results of one-way ANOVA show that there is a significant mean difference between utilization $(\mathrm{F}$ $=49.99$ and $\mathrm{P}=0.000$ ) categories at less than $1 \%$ significance level.

Table 2: The relationship between economic factors and information utilization

\begin{tabular}{lcccccccc}
\hline Variable & Categories & $\mathrm{N}$ & Mean & Std. Dev & Minimum & Maximum & $\mathrm{F}$ & $\mathrm{P}$ \\
\hline \multirow{5}{*}{ On farm income } & Low & 52 & 14080 & 8429 & 3305 & 38545 & & \\
& Medium & 83 & 25294 & 12504 & 2410 & 51800 & & \\
& High & 16 & 48686 & 13733 & 17145 & 70300 & & \\
& Total & 151 & 23911 & 15117 & 2410 & 70300 & $57.616 * * *$ & 0.000 \\
\hline \multirow{5}{*}{ Off farm income } & Low & 52 & 2256 & 1251 & 200 & 6500 & & \\
& Medium & 83 & 3077 & 2223 & 225 & 9945 & & \\
& High & 16 & 3726 & 2197 & 1050 & 8000 & & \\
& Total & 151 & 2863 & 1987 & 200 & 9945 & $4.63 * *$ & 0.011 \\
Total coffee farm size & Low & 52 & 1.36 & 0.35 & 0.13 & 2.00 & & \\
& Medium & 83 & 1.71 & 0.36 & 1.00 & 3.00 & & \\
& High & 16 & 2.38 & 0.41 & 1.50 & 3.00 & & \\
\hline \multicolumn{5}{l}{ Sources: Own study (2017); Note that; $* * * * *$ significant at $1 \%$ and 5\% probability level, respectively, N= Sample size }
\end{tabular}

\section{Institutional factors}

Proximity to a market place is important to purchase and sell different agricultural products and exchanging different information between producers, consumers, traders and utilized other social services. As indicated in table 3 mean total distance of household from nearest town were 4.60 $\mathrm{km}$ and standard deviation $1.80 \mathrm{~km}$. The mean distance of households between low, medium and high categories were $5.2,4.10,5.23 \mathrm{~km}$ with the standard deviation of $2.20,1.33,1.94 \mathrm{~km}$ respectively. The results of the mean test using one-way ANOVA indicated that, there is significant $(\mathrm{F}=8.016$ and $\mathrm{P}=0.000)$ between the respondents among the three information utilization categories.
Extension contact is the most important information dissemination means. In (Table 3) the total mean number of extensions contact of the respondents' in low, medium and high coffee production package information utilization category was 17.62 with the standard deviation of 7.4 days respectively. While the mean number of extensions contact for low, medium and high information utilization category was $17.7,17.4$, and 18.63 with the standard deviation of $7.5,6.95$, and 8.5 days respectively. The one-way ANOVA analysis test shows that there is statistically significant difference among respondents' in coffee package information utilization $(\mathrm{F}=0.192$ and $\mathrm{P}=$ 0.825 ) based on their extension participation at less than $5 \%$ probablity level, respectively.

Table 3: Relationship of institutional variables with information utilization

\begin{tabular}{lcllccccc}
\hline \multicolumn{1}{c}{ Variable } & Categories & $\mathrm{N}$ & Mean & Std. Dev & Minimum & Maximum & $\mathrm{F}$ & $\mathrm{P}$ \\
\hline \multirow{3}{*}{ Distance from } & Low & 52 & 5.20 & 2.20 & 1.00 & 9.00 & & \\
nearest town & Medium & 83 & 4.10 & 1.33 & 1.50 & 8.00 & & \\
& High & 16 & 5.23 & 1.94 & 2.00 & 9.00 & & \\
& Total & 151 & 4.60 & 1.80 & 1.00 & 9.00 & $8.016^{* * * *}$ & 0.000 \\
\hline \multirow{2}{*}{ Number of } & Low & 52 & 17.70 & 7.74 & 6.00 & 36.00 & & \\
extension & Medium & 83 & 17.40 & 6.95 & 6.00 & 32.00 & & \\
contact & High & 16 & 18.63 & 8.50 & 6.00 & 30.00 & $0.192 \mathrm{NS}$ & 0.825 \\
& Total & 151 & 17.62 & 7.35 & 6.00 & 36.00 & & \\
\hline
\end{tabular}

Sources: Own study (2017); Note that; *** is significant at 1\% profanity level and NS: non-significant; $N=$ Sample size 
Table 4: Relationship of social participation (Idir) and radio use frequency with information utilization

\begin{tabular}{|c|c|c|c|c|c|c|}
\hline \multirow[t]{2}{*}{ Categories } & \multicolumn{4}{|c|}{ Frequencies of radio use } & \multirow[t]{5}{*}{$\chi^{2}$} & \multirow[t]{5}{*}{$\mathrm{P}$} \\
\hline & Never & Sometimes & Always & Total & & \\
\hline Low & 4 & 42 & 6 & 52 & & \\
\hline Medium & 0 & 53 & 30 & 83 & & \\
\hline High & 0 & 8 & 8 & 16 & & \\
\hline Total & 4 & 103 & 44 & 151 & $19.142 * * *$ & 0.001 \\
\hline
\end{tabular}

Source: Own study (2017); Note that: *** is significant at 1\% probability level

The frequency of radio use in this study shows pertaining to the usage and radio listening habits of the sample respondents. The results in the above (Table 4) shows 4 (2.6\%) sample respondents not accessed and use radio, 103 (68\%) respondents use radio sometimes and $44(29.4 \%)$ used radio always. The Chi-square test result $\left(\chi^{2}=19.142\right.$ and $\mathrm{P}=0.001)$ for information utilization categories indicates that, there is a significant relationship between radio uses and respondents in low, medium and high categories at $1 \%$ significant level.

\section{Psychological variables}

Information seeking behavior is the extent to which an individual is ready to obtain information from different sources on various tasks she/he performs. The results in (Table 5) reveals that $44(29.1 \%), 59$ (39\%), and $48(31.9 \%)$ respondents were seeking information rarely, sometimes and always respectively. The statistical test of chi-square indicates that there is positive and significant $\left(x^{2}=\right.$ 12.331 and $\mathrm{p}=0.015$ ) association between information seeking behavior of the respondents.

Table 5: Relationship of information seeking behavior with information utilization

\begin{tabular}{|c|c|c|c|c|c|c|}
\hline \multirow{2}{*}{ Categories } & \multicolumn{3}{|c|}{ Information seeking behavior } & \multirow{2}{*}{$\mathrm{N}$} & \multirow{2}{*}{$x^{2}$} & \multirow{2}{*}{$\mathrm{P}$} \\
\hline & Rarely & Sometimes & Always & & & \\
\hline Low & 13 & 27 & 12 & 52 & & \\
\hline Medium & 30 & 26 & 27 & 83 & & \\
\hline High & 1 & 6 & 9 & 16 & & \\
\hline Total & 44 & 59 & 48 & 151 & $12.331 * *$ & 0.015 \\
\hline
\end{tabular}

Source: Own study (2017); Note: ** is significant at 5\% probability level; $N S=$ non-significant respectively

\section{Influence of independent variables on the dependent variable}

From the ordinal logistic regression model a positive estimated coefficient implies that the higher information utilization in coffee packages and practices the higher the values of explanatory variables. The estimated sign implies a unit change in the individual independent variables have in information utilization in coffee package and practices when all other variables are remaining constant. For dummy independent variables, the odd ratio was expressed in comparison to the base category $(\mathrm{x}=0)$. For continuous independent variables, the odd ratio was expressed for a oneunit change of the independent variable.

Age of the Household Head: Age of the respondents was hypothesized that it has a negative relationship with the dependent variable. The result of the ordered logit regression model has shown that, age has negatively affected the dependent variable at $5 \%$ significant level. Odds ratio suggested as other variables remain constant oneyear increase in age of household would cause information utilization of coffee packages decreases by a factor of 0.893 in versus to medium and low perception. The possible explanation for this condition is that, young farmers are strong and eager to utilize recommended coffee packages practice as compared to old farmers. Also, elder farmers tend to be risk averse and may avoid innovations in an attempt to avoid risk associated with the initiative, because some of the technologies to be used, sunk costs have to be incurred. This study is similar with the study conducted by Rukuniet al., (2006) who reported, that being older creates a conservative feeling among farmers and hence resistance to change. The study also confirms the findings of Sanusiet al., 
(2004) and Ayoolaet al., (2012) imply that farmers might not be energetic and excited enough to embark on long term investment in coffee plantation as the age increase.

Table 6 Parameters estimates of the ordinal logistic regression model

\begin{tabular}{llllll}
\hline \multicolumn{1}{c}{ Independent variables } & Estimate & Std. Error & Wald & Sig. & Odd ratio \\
\hline Age & -0.113 & 0.039 & 8.282 & $0.004^{* * *}$ & 0.893 \\
Household size & 0.538 & 0.224 & 5.752 & $0.016^{* *}$ & 1.710 \\
Education level & 0.143 & 0.084 & 2.920 & $0.087 \mathrm{NS}$ & 1.154 \\
Total coffee farm & 2.348 & 0.833 & 7.943 & $0.005^{* * *}$ & 10.381 \\
On-farm income & $6.606 \mathrm{E}-005$ & $2.726 \mathrm{E}-005$ & 5.871 & $0.015^{* *}$ & 1.000 \\
Livestock owner ship & 0.289 & 0.164 & 3.110 & $0.078 \mathrm{NS}$ & 1.335 \\
Off-farm income & $1.761 \mathrm{E}-005$ & 0.000 & 0.020 & $0.886 \mathrm{NS}$ & 1.000 \\
Social participation & 1.463 & 0.624 & 5.497 & $0.019 * *$ & 4.319 \\
Distance from market place & -0.135 & 0.138 & 0.967 & $0.325 \mathrm{NS}$ & 0.874 \\
Access to credit service & 0.230 & 0.489 & 0.220 & $0.639 \mathrm{NS}$ & 1.259 \\
Number of extensions contact & 0.052 & 0.034 & 2.294 & $0.130 \mathrm{NS}$ & 1.053 \\
Frequency of radio uses & 1.029 & 0.545 & 3.564 & $0.059^{* *}$ & 2.798 \\
Innovation proneness & 0.226 & 0.298 & 0.574 & $0.449 \mathrm{NS}$ & 1.254 \\
Information seeking behavior & 0.343 & 0.315 & 1.188 & $0.276 \mathrm{NS}$ & 1.409 \\
Willingness to share information & 1.390 & 0.514 & 7.309 & $0.007 * * *$ & 4.015 \\
Atti. toward coffee package & 1.791 & 0.693 & 6.685 & $0.010^{* * *}$ & 5.995 \\
technology & 12.083 & 3.186 & 14.382 & .000 & .000 \\
\hline Cut = 1 & 18.334 & 3.569 & 26.393 & \\
Cut = 2 & & &
\end{tabular}

Source: Model output (2017); -2 Log Likelihood $=282.039$, chi-square test $=146.696$, High base category Significant $=0.000$, pseudo $\mathrm{R}^{2}$ (Nagelkerke) $=0.735 * * *$ and $* *$ is significant at $1 \%$ and $5 \%$ probability level and NS $=$ non- significant .

Household size:From the econometric ordered logit model result, it is observed that number of family size has a positive and significant influence on utilization categories at $5 \%$ probability level.The result shown in table 6 indicated that, holding the other variables constant, one unit increase in adult equivalent, would cause utilization of coffee package information increases by a factor of 1.710 in versus to medium and low perception. The probable reason behind is that a farmer with larger household size relatively supplies more labor force who participates in coffee production activities. The This result agreed with Hassenet al., (2012) who reported that farmer's decision on utilization of improved practices and technologies becomes dependent on the availability of labor force in the household. The conducted by Assefa and Yared (2016) is similar with this study who reported that households that have a larger number of working group members were more likely to be included in utilization of agricultural information.

On-farm income: The model result revealed that on farm income has positive and significant influence on information utilizations in coffee productions package at less than $5 \%$ level of significance. Holding the other variables constant, a one Birr increase on farm income would cause information utilization in coffee packages increases by a factor of 1 versus to the medium and low perception. This might be respondents have more income privately will purchase different farm inputs and implements as well and get more profit by selling the product obtained from the farm. This is in line with Lalisa (2016) who reported that households who earn more on-farm income are more likely to adopt new production packages. In the same line, Kidane (2001), Degnetet al., (2001) and Getahun (2004) reported that farm income has a positive influence of households in adoption of improved agricultural technologies.

Coffee farm size: coffee farm size was significantly and positively influencing information utilization at less than 5\% significance level. The model output indicates that by a 1 hectare increase in coffee farm size, would cause information utilization in coffee production package by a factor of 10.381 times more versus the medium and low perception when the other variables remain constant. This might be a farmer with large farm size would plant more coffee seedling, and 
relatively harvest more yield and more flow of money into the family, hence, relatively strong purchasing power to buy coffee package inputs. This study is in line with the study conducted by Okwu and Lorkaa (2011) who reported that farmers with large farms are likely to be better informed, richer and keener in searching for information on improved technologies. It is also similar to the study conducted by Gebregziabher (2012) who reported that the farm size has a positive and significant influence on utilizations of new agricultural practices.

Social participation: The ordinal logit model result indicates that social participation has a significant and positive influence on coffee packages information utilization by $5 \%$ significant level. Odds ratio suggested as other variable remain constant, increases in frequency score of social participation would cause coffee package information utilization to increase by the factor of 3.281 versus in the medium and lower category. This implies that as the participation of farmers in social organization increase, the probability of information utilization in coffee packages and practices also increases. This study is in line with the study conducted by Getahun (2008) who reported that social participation increases utilization of wheat production packages.

Frequencies of radio use: The result of the model indicates that the frequency of radio listening shows a significant and positive influence information utilization at 5\% level of significance. The odds ratio suggested that increase in frequency of radio listening would cause utilization of coffee package information by the factors 2.798 versus in the medium and lower category when the other factor kept constant. This might be due to the fact that farmers who have high (more frequently listening) have more utilized information than those farmers who have no/less radio exposure. The study is similar with study was conducted by Tilahun (2008) who reported those who have high exposure (more frequently listen) have more access and use information than those who have no/less radio listing. This study is in line with (Lwoga, 2010; Mtega, 2008); Olaleyeet al., 2009) which indicated rural radio, is one of the services offered by Telecentres, has gained a great role in Tanzania.

Willingness to share information: The model output reveals that willingness to share information positively influences information utilization in coffee production package at $1 \%$ significance level. Odds ratio suggested as other variable remain constant, increase, willingness to share information would cause coffee package information utilization by the factor of 4.015 versus to unwillingness category when the other category remain constant. This might be because of farm households who are willing to share information, can easily communicate, access and utilize agricultural information. This result is in line with the study conducted by Tsadikan (2016). The study conducted by Getahun (2008) has similar results.

Attitude towards coffee package technology: The model output reveals that the attitude of farmers towards coffee package technology is positively influences, information utilization at 5\% significance level. Odds ratio suggested as other variable remain constant, the increase in positive attitude towards higher level coffee package technology would affect more coffee package information utilization by the factor of 5.995 versus to the negative attitude. Positive attitude towards improved farming is one of the factors which could speed up the farm change process (Tadese, 2008).

\section{CONCLUSION AND SUGGESTIONS}

Coffee is one of the major cash and exported commodity in Ethiopia in general and Homa district in particular. Even though it is precious product to the areas farmers harvests low amount of yield which arises from less and infrequently information utilization in modern coffee production packages and its practice technologies by farmers in the area. The result of one-way ANOVA and Chi-square test more of the hypothesized variables were significantly related with dependent variable and some of them were insignificant relation with dependent variable. Further analysis was done by using ordered logit econometric model to know the detail influence of different explanatory variables on dependent variable. Age of the household size, on-farm income, coffee farm size, a frequency of radio use, social participation, and willingness to share information and attitude toward coffee packages technology were found to be significantly affect at less than $1 \%$ and $5 \%$ significance level. On the basis of this study the following recommendations are suggested for practical action and future studies. Age of the respondents had significantly and negatively influencing the information utilization. Therefore, current 
extensions systems will need to strengthen coffee packages information dissemination as well as need to put a concerted effort to address the elder group of farmers through facilitating multi extension dissemination.

Household size had a significant and positive relationship with information utilization in coffee production packages. For more valuable it is recommended that Woreda coffee, tea and market development authority should be addressing labor supply gaps through organized small family size work to gather in order to manage all activities in a given work plan and seasons. The study revealed that farm income had a significant and positively related with information utilization. Therefore, the rural development strategy should give priority attention to promote on-farm diversification technologies by providing sustainable technical training for small household farmers.

Coffee farm size was significantly and positively related with the dependent variable. Therefore, wise utilization of coffee farm in the study area should be strengthening, since the coffee plant in the study area is very old, it is recommended that stumping or uprooting the old coffee trees which is not improved by stumping and replacing with the new variety coffee seedling. Participation of farmers in social organization is significantly influencing information utilization. The presence relevant organizations in the study area increase the probability of farmers to utilize more coffee production package. Therefore, it is recommended that all local planners and others concerned bodies should be given priority attentions to strengthen public institutions and incorporating it in to agricultural development planning in order to facilitate farmers participation in organization. This enables them to have more information about the existence of the available packages.

\section{ACKNOWLEDGEMENT}

I would like to be grateful for the unconditional love and faithfulness of the God. Next I would like to thank to a large number of individuals for their encouragement and help while conducting this study. First and foremost, to Mr. Guta Ragasa and Akalu Dafisa to whom I am duly bound to express my appreciation for their valuable and constructive comments during thesis writing. I also remain thankful, all RDAE department members specially Mr. TammiruChalchisa for his contribution and sharing his knowledge for my study. I also felt great to express this thanks to the enumerators who assisted this work successfully and key informants and sample respondents who participated in the study for sparing their precious time and hospitality of the communities without which this document could have not been written. My last, but by no means the least, words of thanks go to my wife KonjitGobena for her encouragement in shouldering all family responsibilities during the course of my postgraduate study and for her continual support which was a force for me to bring the study into this stage.

\section{REFERENCES}

Anthony, F., Bertrand, B., Quiros, O., Wilches, A., Lashermes, P., Berthaud, J. and Charrier, A., 2001.Genetic diversity of wild coffee (Coffeaarabica L.) using molecular markers. Euphytica, 118 (1): 53-65.

Assefa, M. and Yared, M., 2016.Access to and Utilization of Agricultural Information by Smallholder Coffee Farmers in Deder District, Eastern Hararghe Zone, Oromia National Regional State, Ethiopia (Doctoral dissertation, Harmaya University).

Ayoola, J.B., Ayoola, G. B. and Ladele, A. A. 2012.An assessment of factors constraining coffee production and marketing in Nigeria.International journal of science and nature 3(3): 678-683

Bachhav, N.B., 2012. Information needs of the rural farmers: A study from Maharashtra, India: a survey. Library Philosophy and Practice.

Banmeke, T.O.A. and Ajayi, M.T., 2008. Farmers' perception of the agricultural information resource centre at Ago-Are, Oyo State, Nigeria.Editorial Board, 1(1): 22-29.

C S A, 2015.Report on Area and Production of Major Crops (1). Addis Ababa, Ethiopia: Central statistical Agency.

Degnet A, Belay K and Aregay, W., 2001.Adoption of high yielding maize varieties in Jimma zone. Ethiopian Journal of Agricultural Economics. (5): 41-62 
Gebregziabher, H., 2012. Economic Efficiency of Groundnut Production: A Comparative Study of Local Seed Business Project Participant and Non-Participant Farmers in Babile District, Eastern Ethiopia (Doctoral dissertation, Haramaya University).

Getahun S., 2008. Access to and Utilization of Agricultural Information on Bread Wheat: The case of small holder farmers in TachGayint District, South Gondar Zone, Ethiopia tern highlands of Ethiopia: The double hurdle approach. Journal of Research Economics and International Finance, 1(2): 39-49.

Hassen B, Bezabeh E, Belay K and Jema H., 2012. Determinants of chemical fertilizer technology adoption in north eastern highlands of Ethiopia: The double hurdle approach. Journal of Research Economics and International Finance, 1(2): 39-49.

HomaWoreda Agricultural and Natural Resource Office and Coffee and Tea market development authority Office. 2017. 'The taken from basic data of the'.

Kidane G, 2001. Factors Influencing the Adoption of New Wheat and Maize Varieties in Tigray, Ethiopia: The Case of HawzienWoreda. An M. Sc. Thesis Presented to School of Graduate Studies of Alemaya University, Ethiopia.

Lalisa, D., 2016. Access to and utilization of agricultural information on bread wheat by smallholder farmers of GedabHasasa District, West Arsi Zone, Oromia Regional State, Ethiopia. Haramaya University, Haramaya

Lwoga, E.T. 2010. Bridging the Agricultural Knowledge and Information Divide: The Case of Selected Telecenters and Rural Radio in Tanzania. The Electronic Journal of Information Systems in Developing Countries, 43 (6): $1-14$

Lwoga, E.T., Ngulube, P. and Stilwell, C., 2010. M anaging indigenous knowledge for sustainable agricultural development in developing countries: Knowledge management approaches in the social context. The International Information and Library Review, 42(3):174-185.

\footnotetext{
Market Overview 2018. https://www.export.gov/article? id=Ethiopia Market-Overview
}

Mayne, R., Tola, A. and Kebede, G. 2002. Crisis in the birth place of coffee, Oxfam International research paper, Oxfam International.

Meyer, H.W.J., 2000. The transfer of agricultural information to rural communities (Doctoraldissertation, University of Pretoria).

Mtega, W., 2008. The Use of Telecentres in Tanzania: A Case Study of Kilosa District. Masters Dissertation, University of Dar es Salaam.

Okwu, O.J. and Lorkaa, T.I. 2011.An assessment of farmers' use of new information and communication technologies as sources of agricultural information in Ushongo Local Government Area, Benue State, Nigeria.Journal of Sustainable Development in Africa, 13 (2):41-52

Olaleye, R.S., Gana, F.S., Umar, I.S., Ndanisa, M.A. and Peter, E.W., 2009. Effectiveness of Radio in the Dissemination of Agricultural Information among Farmers in Edu Local Government Area of Kwara State, Nigeria.Continental Journal of Agricultural Science (3): 1-6.

http://www.wiloludjournal.com/ojs/index.php/ cjAgsc/article/viewArticle/866

Rukuni, M., Tawonezvi, P., Eicher, C., MunyukiHungwe, M., and Matondi, P., 2006.Zimbabwe's Agricultural Revolution Revisited. University of Zimbabwe Publications, Harare

Sanusi, R.A., M.O. Adejumo and Shittu T.R., 2006.Analysis of Coffee Output Viarations as Correlate of Wheather Variable in Nigeria. In: Proceeding of the $21^{\text {st }}$ International Conference on Coffee Science Organized by ASIC, Held in Montpellier France. 11 - 15th September, 2006. Available on line @ www.asic-cafe.org.

Tadesse, D., 2008. Access and utilization of agricultural information by resettler farming households: the case of MetemaWoreda, North Gondar, Ethiopia (Doctoral dissertation, Haramaya University).

Tefera, A. and Tefera, T., 2013.Ethiopian Coffee Annual Report.Gain report ET-1302, USDA.

Tesfu, K., 2012. Coffee quality and productivity as basic factors for sustainability in Ethiopia.2st African Coffee Sustainability Forum February 15th, 2012, United Nations Conference Center 
134 Factors Affecting Information Utilization in Coffee Production Packages Among Smallholder Farmers

at Addis Ababa (UNCC-AA), Addis Ababa, Ethiopia.

Tilahun S., 2008. Access to and utilization of family planning information among rural women in Adama District, Oromia national regional state, Ethiopia.
Tsadkan, A., Okoyo, D. and Ndemo, E., 2016. Access to and Utilization of Agricultural Information on Groundnut Production Package by Smallholder Farmers in Babilie District, East Hararghe Zone, Ethiopia (Doctoral dissertation, Harmaya University). 